\title{
Ring Opening Polymerization of Oxetane by Use of Silicate Gel of Rare Earth Metal
}

\author{
Osamu Moriya, ${ }^{1, \dagger}$ Shin-ichi Yamamoto, ${ }^{1}$ Toshio Sugizaki, ${ }^{2}$ Jun Maeda, ${ }^{2}$ \\ Atsuko KameJima, ${ }^{2}$ Takeo Kumon, ${ }^{3}$ and Toshifumi KageYama ${ }^{3}$ \\ ${ }^{1}$ Department of Applied Chemistry, National Defense Academy, Hashirimizu, Yokosuka 239-8686, Japan \\ ${ }^{2}$ Research Laboratory, Lintec Co., Nishiki-cho, Warabi 335-0005, Japan \\ ${ }^{3}$ Department of Industrial Chemistry, Kanto Gakuin University, \\ Mutsuura, Kanazawa-ku, Yokohama 236-8501, Japan
}

(Received October 21, 2004; Accepted January 19, 2005; Published April 15, 2005)

\begin{abstract}
The gels of the rare earth metal silicate such as yttrium, neodymium, or samarium were found to be the effective solid catalysts for the ring opening polymerization of oxetane. The silicate gels were prepared by the cogelation of sodium metasilicate and the rare metal chloride from an acidic aqueous solution through the neutralization by an aqueous ammonia, the surface areas of which were in the range from 142 to $213 \mathrm{~m}^{2} \mathrm{~g}^{-1}$. The ring opening polymerization of oxetane proceeded readily at $20^{\circ} \mathrm{C}$ in the presence of a catalytic amount of the silicate gels, in which the content of the rare earth metal was $10 \mathrm{~mol} \%$ to oxetane. The silicate gel of yttrium, which enabled the quantitative formation of the corresponding polymer, was the most effective solid acid among those of the rare earth metals employed in this work. [DOI 10.1295/polymj.37.262]

KEY WORDS Metal Silicate / Rare Earth Metal / Oxetane / Ring Opening Polymerization / Solid Acid /
\end{abstract}

In the practical procedures for effective ring opening reaction of cyclic ethers, the uses of various solid materials have been well known. ${ }^{1,2}$ In the solid catalysts, several derivatives based on silica such as aluminum silicates, titanium silicates, natural clay minerals and zeolites are reported to be effective for the ring opening reaction leading to 1,2-difunctionalized compounds from oxiranes. ${ }^{3-6}$ Recently, in polymer synthesis, the silica derivatives have been employed for the well defined ring opening polymerization of 1,2-epoxide $^{7}$ and lactones. ${ }^{8-10}$ The enhancement of such ring opening reaction is explained by Brønsted and Lewis acidity with an appropriate reaction environment provided by the catalysts. On the other hand, in the fields of organic synthesis, the rare earth metal ions are successfully utilized as the effective Lewis acids. ${ }^{11,12} \mathrm{Al}$ though rare earth metals does not act as the simple Lewis acids, their alkoxides and complexes are also applied to synthesis of polymeric compounds through ring opening polymerization. ${ }^{13-17}$ From those facts, the silicate gel of rare earth metal, which shows Brønsted and/or Lewis acidity, are thought to be a promising useful solid catalyst. However, the previous investigations concerning the rare earth metal silcates have been focused on their physical and optical properties. ${ }^{18-23}$ The catalytic use of such silicates in organic reactions has not been developed so far and seems to be left as an interesting theme. ${ }^{24}$

Very recently, the polymeric products obtained from oxetanes have been attracted much attention, which can be used for adhesives instead of those from oxiranes. ${ }^{25-28}$ The ring opening polymerization of oxetanes has been usually conducted by the use of cationic species. ${ }^{29-31}$ These previous works promise that the silicate gel of rare earth metal is effective for the ring opening polymerization. Furthermore, the use of solid acid, which can be removed easily from a reaction mixture and reused, should provide a practical and convenient procedure for polymer synthesis. ${ }^{32}$ On the basis of such considerations, we have started the investigations on the catalytic use of rare earth metal silicate for ring opening polymerizations. In this preliminary report, oxetane was chosen as a starting material and catalytic activities of three kinds of the silicate gels such as yttrium (1), neodymium (2), and samarium (3) were examined.

\section{EXPERIMENTAL}

\section{General}

${ }^{1} \mathrm{H}$ NMR and ${ }^{13} \mathrm{C}$ NMR spectra were obtained on a JEOL FX-270 and JNM A-500 spectrometer in $\mathrm{CDCl}_{3}$. IR spectra were recorded on a JASCO FT/ IR 230. The specific surface areas were obtained by the Brunaur-Emmett-Teller (BET) method with a Collter Omnisorp 100CX using nitrogen as the absorbate. Gel permeation chromatographic (GPC) analysis was carried out on a TOSO HLC-8020 chromatograph

${ }^{\dagger}$ To whom correspondence should be addressed (Tel: +81-468-41-3810, Fax: +81-468-44-5901, E-mail: moriyaos@nda.ac.jp). 
Solid Acid for Polymerization of Oxetane

Table I. Preparation of rare earth metal silicate gel

\begin{tabular}{|c|c|c|c|c|c|c|}
\hline $\begin{array}{c}\text { Silicate } \\
\text { gel } \\
\text { (Metal) }\end{array}$ & $\begin{array}{c}\text { Yield of } \\
\mathrm{Si} \\
\%\end{array}$ & $\begin{array}{c}\text { Yield of } \\
\text { metal } \\
\%\end{array}$ & $\begin{array}{c}\text { Content of } \\
\mathrm{Si}^{\mathrm{a}} \\
\mathrm{mmol} / \mathrm{g}\end{array}$ & $\begin{array}{c}\text { Content of } \\
\text { metal }^{\mathrm{a}} \\
\mathrm{mmol} / \mathrm{g}\end{array}$ & $\begin{array}{l}\text { Molar } \\
\text { ratio of } \\
\text { Si/Metal }\end{array}$ & $\begin{array}{c}\text { Surface area } \\
\mathrm{m}^{2} / \mathrm{g}\end{array}$ \\
\hline $1 \mathrm{a}(\mathrm{Y})$ & 61 & 58 & 5.49 & 2.59 & $2.1 / 1$ & 150 \\
\hline $1 b(Y)$ & 65 & 88 & 11.68 & 1.76 & $6.6 / 1$ & 195 \\
\hline $1 c(Y)$ & 68 & 71 & 8.59 & 1.01 & $8.5 / 1$ & 195 \\
\hline 1d (Y) & 65 & 68 & 14.89 & 0.78 & $19.0 / 1$ & - \\
\hline 2a $(\mathrm{Nd})$ & 79 & 86 & 5.50 & 3.02 & $1.8 / 1$ & 142 \\
\hline $\mathbf{2 b}(\mathrm{Nd})$ & 80 & 70 & 9.78 & 1.48 & $6.6 / 1$ & - \\
\hline $\mathbf{2 c}(\mathrm{Nd})$ & 65 & 70 & 11.71 & 1.11 & $10.6 / 1$ & - \\
\hline 3a $(\mathrm{Sm})$ & 31 & 32 & 2.74 & 1.43 & $1.9 / 1$ & 213 \\
\hline
\end{tabular}

${ }^{\mathrm{a} E s t i m a t e d ~ b y ~ g r a v i m e t r i c ~ a n a l y s i s . ~}{ }^{\mathrm{b}}$ Measured by BET method using nitrogen as the absorbate.

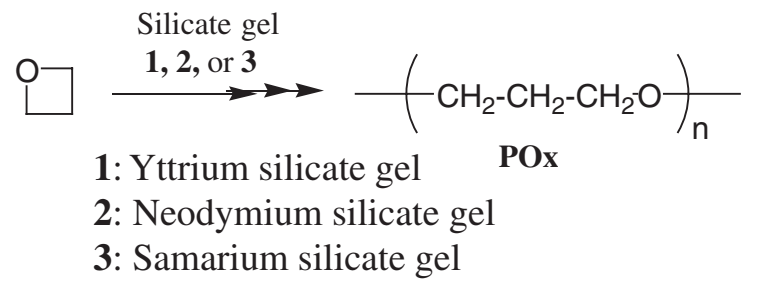

Scheme 1.

equipped with a refractive index detector. TSK gel $\mathrm{G} 2500 \mathrm{H}, \mathrm{G} 2000 \mathrm{H}$, and $\mathrm{G} 1000 \mathrm{H}$, were connected in series and tetrahydrofuran (THF) was used as an eluent. Calibration for number-average molecular weight $\left(M_{\mathrm{n}}\right)$ and polydispercity $\left(M_{\mathrm{w}} / M_{\mathrm{n}}\right)$ was performed using standard polystyrenes. The alcohols used as the additives were distilled over magnesium metal after the treatment with sodium metal. Oxetane was just distilled under argon atmosphere before use. All other substrates were the best commercially available reagent grade and distilled before use. Solvents employed for the reactions were distilled over an appropriate metal or a metal hydride before use.

\section{Gravimetric Analysis}

A weighed sample was oxidized by perchloric acid at $90^{\circ} \mathrm{C}$ in a platinum crucible until all of the liquid was vaporized, and the resulting precipitates were further dried at $900^{\circ} \mathrm{C}$. The precipitates, regarded as $\mathrm{SiO}_{2}$ and the rare earth metal oxide, were weighed. Next, the precipitates were treated as same as above with the $1 / 1(\mathrm{v} / \mathrm{v})$ mixture of perchloric acid and hydrofluoric acid. The content of silicon $(\mathrm{Si})$ were calculated as $\mathrm{SiO}_{2}$ from the weight loss in these two steps, and that of the rare metal such as yttrium (Y), neodymium $(\mathrm{Nd})$, or samarium $(\mathrm{Sm})$ was estimated from the weight of the residual ash regarded as the oxide.

\section{Preparation of Rare Earth Metal Silicate Gel}

Typical procedure was as follows: To a solution of sodium metasilicate $\left(\mathrm{Na}_{2} \mathrm{SiO}_{3}\right)(28.4 \mathrm{~g}, 0.10 \mathrm{~mol})$ in water $(100 \mathrm{~mL}), \mathrm{pH}$ value of which was adjusted to be $c a .1$ by using diluted hydrochloric acid (6 [M]), yttrium(III) chloride hexahydrate $\left(\mathrm{YCl}_{3}, 15.2 \mathrm{~g}, 0.05\right.$ $\mathrm{mol})$ in water $(100 \mathrm{~mL})$ was added. The aqueous solution was neutralized to $\mathrm{pH}=7$ by $10 \%$ of aqueous ammonia solution, which was added portion wise for over $3 \mathrm{~h}$ at room temperature. The solid precipitated from the solution was collected and washed several times with water and acetone. After drying at $700^{\circ} \mathrm{C}$ for $3 \mathrm{~h}$ under air, the silicate gel 1a $(11.1 \mathrm{~g}, 61 \%$ based on $\mathrm{Si}, 58 \%$ based on Yttrium) was obtained. The contents of silicon and yttrium in 1a were estimated by the results of gravimetric analysis and the specific surface area by BET method.

Analogously, the silicate gels involving several different ratios of silicon $(\mathrm{Si})$ and yttrium $(\mathrm{Y}, \mathbf{1 b}-\mathbf{d})$ were prepared by changing the feed ratios of the starting materials. Further, other gels $\mathbf{2 a - c}$ and $\mathbf{3 a}$ were also prepared from $\mathrm{Na}_{2} \mathrm{SiO}_{3}$ with neodymium chloride $\left(\mathrm{NdCl}_{3}\right)$ and samarium chloride $\left(\mathrm{SmCl}_{3}\right)$, respectively, in a similar manner as above. The analytical data of $\mathbf{1}, \mathbf{2}$, and $\mathbf{3}$ was shown in Table I.

\section{Ring Opening Polymerization of Oxetane}

Typical procedure was as follows: The silicate gel 1a $(0.26 \mathrm{~g}, \mathrm{Y}=0.69 \mathrm{mmol}$ equiv, $10 \mathrm{~mol} \%)$ in a glass tube equipped with rubber septum was degassed and substituted with nitrogen at room temperature. Benzene $(4 \mathrm{~mL})$ and oxetane $(0.42 \mathrm{~g}, 6.90 \mathrm{mmol})$ were injected by syringe and, then, the solution was stirred at $20^{\circ} \mathrm{C}$ for an appropriate time. After the reaction, 1a was filtered off and washed with methanol several times. The filtrate and washings were combined and evaporated under reduced pressure. The residual oil was washed with $n$-hexane and dried under reduced pressure $(c a .5 \mathrm{mmHg}$ ) at room temperature to obtain the polymeric product of oxetane (POx) $(0.40 \mathrm{~g}$, 95\%); IR (neat) 3450 (OH, weak), $2980\left(\mathrm{CH}_{2}\right.$, strong), $2850\left(\mathrm{CH}_{2}\right.$, strong $), 1360\left(\mathrm{CH}_{2}\right.$, medium $), 1120(\mathrm{C}-\mathrm{O}$, strong) $\mathrm{cm}^{-1} ;{ }^{1} \mathrm{H}$ NMR $\left(\mathrm{CDCl}_{3}\right) \delta 1.84\left(\mathrm{~m},-\mathrm{CH}_{2}-\right)$, $3.49\left(\mathrm{~m},-\mathrm{O}-\mathrm{CH}_{2}-\right) ;{ }^{13} \mathrm{C} \mathrm{NMR}\left(\mathrm{CDCl}_{3}\right) \quad \delta \quad 30.19$ 


\section{O. MORIYA et al.}

Table II. Polymerization of oxetane in the presence of silicate gel

\begin{tabular}{|c|c|c|c|c|c|c|}
\hline \multirow[b]{2}{*}{ Run } & \multicolumn{2}{|c|}{ Silicate gel } & \multicolumn{4}{|c|}{$\mathbf{P O x}^{\mathrm{a}}$} \\
\hline & (Metal) & $\begin{array}{l}\text { Molar ratio of } \\
\mathrm{Si} / \text { Metal }\end{array}$ & $\begin{array}{c}\text { Conversion }^{\mathrm{b}} \\
\%\end{array}$ & $\begin{array}{c}\text { Yield }^{\mathrm{c}} \\
\%\end{array}$ & $M_{\mathrm{n}}^{\mathrm{d}}$ & $M_{\mathrm{w}} / M_{\mathrm{n}} \mathrm{d}$ \\
\hline 1 & 1a $(Y)$ & 2.1 & 97 & 95 & 5800 & 3.32 \\
\hline 2 & $1 \mathrm{~b}(\mathrm{Y})$ & 6.6 & 95 & 90 & 4000 & 2.86 \\
\hline 3 & $1 \mathrm{c}(\mathrm{Y})$ & 8.5 & 85 & 83 & 5600 & 3.25 \\
\hline 4 & 1d $(\mathrm{Y})$ & 19.0 & 51 & 43 & 4600 & 2.53 \\
\hline 5 & 2a $(\mathrm{Nd})$ & 1.8 & 75 & 70 & 4900 & 3.01 \\
\hline 6 & $\mathbf{2 b}(\mathrm{Nd})$ & 6.6 & 62 & 60 & 5600 & 3.15 \\
\hline 7 & $2 c(\mathrm{Nd})$ & 10.6 & 60 & 58 & 5400 & 3.51 \\
\hline 8 & $\mathbf{3 a}(\mathrm{Sm})$ & 1.9 & 39 & 34 & 4500 & 4.11 \\
\hline
\end{tabular}

${ }^{\mathrm{a}} 6.90 \mathrm{mmol}$ of oxetene and the silicate gel containing $10 \mathrm{~mol} \%$ of rare earth metal to oxetane were used for the polymerizsation carried out in benzene $(4 \mathrm{~mL})$ at $20^{\circ} \mathrm{C}$ for $18 \mathrm{~h}$. ${ }^{\mathrm{b}}$ Estimated by ${ }^{1} \mathrm{H}$ NMR spectral data.

${ }^{\mathrm{c}}$ Isolated yield based on the weights of the materials. ${ }^{\mathrm{d}}$ Estimated by GPC (polystyrene standards).

Table III. Polymerization of oxetane with silicate gel 1a

\begin{tabular}{|c|c|c|c|c|c|c|c|}
\hline \multirow[b]{2}{*}{ Run } & \multicolumn{3}{|c|}{ Conditions $^{\mathrm{a}}$} & \multicolumn{4}{|c|}{ POx } \\
\hline & $\begin{array}{c}\text { Y/Oxetane } \\
\text { mol \% }\end{array}$ & Additive $^{\mathrm{b}}$ & Solvent & $\begin{array}{c}\text { Conversion } \\
\%^{c}\end{array}$ & $\begin{array}{l}\text { Yield } \\
\%^{d}\end{array}$ & $M_{\mathrm{n}}^{\mathrm{c}}$ & $M_{\mathrm{w}} / M_{\mathrm{n}}^{\mathrm{e}}$ \\
\hline 1 & 1 & - & - & 63 & 60 & 5200 & 2.96 \\
\hline 2 & 10 & - & - & 100 & 100 & 6000 & 2.93 \\
\hline 3 & 1 & - & Benzene & 35 & 25 & 5100 & 3.36 \\
\hline 4 & 5 & - & Benzene & 89 & 85 & 5400 & 3.17 \\
\hline 5 & 10 & - & Benzene & 97 & 95 & 5800 & 3.32 \\
\hline $6^{\mathrm{f}}$ & 10 & - & Benzene & 98 & 95 & 5500 & 3.35 \\
\hline $7^{g}$ & 10 & - & Benzene & 93 & 90 & 5100 & 3.29 \\
\hline 8 & 10 & $\mathrm{MeOH}^{\mathrm{h}}$ & Benzene & 75 & 73 & 2600 & 3.25 \\
\hline 9 & 10 & ${ }^{i} \mathrm{PrOH}^{\mathrm{i}}$ & Benzene & 80 & 75 & 3500 & 2.28 \\
\hline 10 & 10 & ${ }^{n} \mathrm{BuNH}_{2}{ }^{\mathrm{j}}$ & Benzene & 0 & 0 & - & - \\
\hline 11 & 10 & $\mathrm{H}_{2} \mathrm{O}$ & Benzene & 0 & 0 & - & - \\
\hline 12 & 10 & $\mathrm{CH}_{3} \mathrm{CO}_{2} \mathrm{H}$ & Benzene & 99 & 97 & 3100 & 3.32 \\
\hline 13 & 10 & - & Acetone & 69 & 65 & 2500 & 3.78 \\
\hline 14 & 10 & - & $\mathrm{CH}_{2} \mathrm{Cl}_{2}$ & 78 & 73 & 4300 & 3.21 \\
\hline 15 & 10 & - & $\mathrm{CH}_{3} \mathrm{CN}$ & 60 & 58 & 3400 & 3.52 \\
\hline
\end{tabular}

a Polymerzation, using $6.90 \mathrm{mmol}$ of oxetene, was carried out in $4 \mathrm{~mL}$ of solvent at $20^{\circ} \mathrm{C}$. ${ }^{\mathrm{b}} 10 \mathrm{~mol} \%$ of the additive to oxetane was used. ${ }^{\mathrm{C}}$ Estimated by ${ }^{1} \mathrm{H}$ NMR spectral data. ${ }^{\mathrm{e}}$ Estimated by GPC (polystyrene standards). ${ }^{\mathrm{d}}$ Isolated yield based on the weights of the materials. ${ }^{\mathrm{f}}$ The second use of $\mathbf{1 a}$ after the calcination at $300{ }^{\circ} \mathrm{C}$ for $3 \mathrm{~h}$. ${ }^{\mathrm{g}}$ The third use of $\mathbf{1 a}$ after the calcination at $300^{\circ} \mathrm{C}$ for $3 \mathrm{~h}$. ${ }^{\mathrm{h}}$ Methanol. ${ }^{\mathrm{i}}$ iso-Propyl alcohol. ${ }^{\mathrm{j}}$-Butylamine.

$\left(-\mathrm{CH}_{2}-\right), 67.90\left(-\mathrm{O}-\mathrm{CH}_{2}-\right) ; M_{\mathrm{n}}=5800, M_{\mathrm{w}} / M_{\mathrm{n}}=$ 3.32 .

Analogously, the ring opening polymerizations were carried out in the presence of a catalytic amount of the silicate gel $\mathbf{1}, \mathbf{2}$, or $\mathbf{3}$. The results and conditions were listed in Table II. The polymerizations in other solvents and with an additive were carried out under the conditions mentioned above. The results, the solvents, and the additives were listed in Table III. For the time-conversion and the conversion $-M_{\mathrm{n}}$ and $M_{\mathrm{w}} / M_{\mathrm{n}}$ curves, samples were taken by a syringe and used for the measurements of ${ }^{1} \mathrm{H}$ NMR and GPC during the polymerizations, respectively (Table III, Run 5 and 6).

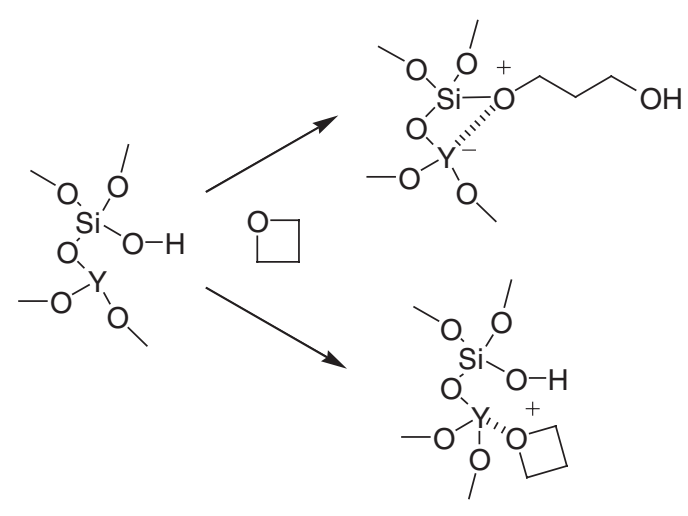

Scheme 2. 


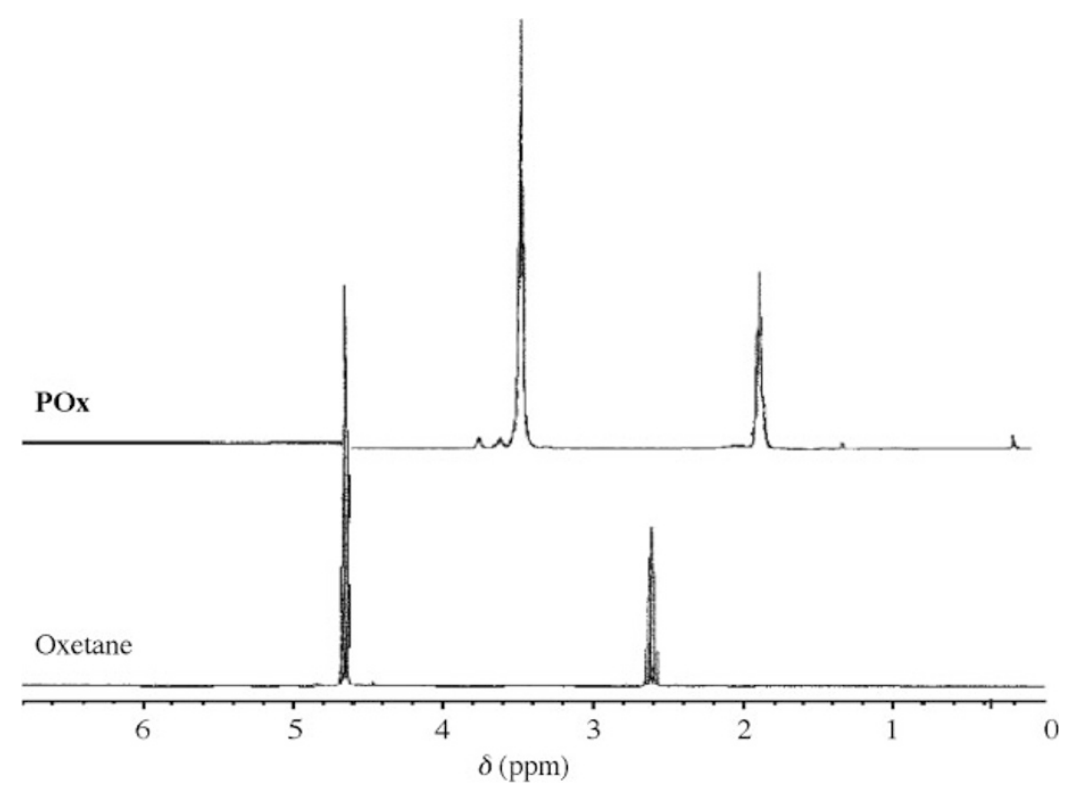

Figure 1. ${ }^{1} \mathrm{H}$ NMR spectra $\left(\mathrm{CDCl}_{3}\right)$ of oxetane and POx (Table II, Run 1).

\section{RESULTS AND DISCUSSION}

\section{Preparation of Silicate Gel}

As shown in Table I, the silicate gels were prepared from $\mathrm{Na}_{2} \mathrm{SiO}_{3}$ and $\mathrm{YCl}_{3}, \mathrm{NdCl}_{3}$, and $\mathrm{SmCl}_{3}$, respectively, through co-gelation. The aqueous solution of sodium metasilicate and the rare earth metal chlorides was acidified by a diluted hydrochloric acid. The $\mathrm{pH}$ value of the solution was adjusted to be $c a$. 1 . Since, in such acidic solution, polymeric or oligomeric silicic acid is reported to be hydrolyzed to monomeric one, which should be favorable to disperse the rare earth metal species. ${ }^{32}$ The precipitation of the silicate gel was performed by careful neutralization, in which $10 \%$ aqueous ammonia solution was added by portions. When sodium hydroxide was used for the treatment, the silicate gels, obtained almost quantitatively, showed a relatively low activity as the solid acid. ${ }^{34}$ This suggested that the difficulty of complete removal of the alkali metal species from the gel products and the presence of the species reduced an acidity of the silicate. Consequently, aqueous ammonia hydroxide, the ionic species of which seemed to be removed by calcination readily, was chosen as a neutralizing reagent to precipitate the silicate gel. The surface areas of the silicate gels measured by BET method were in the range from 142 to $213 \mathrm{~m}^{2} \mathrm{~g}^{-1}$. These values indicated that the gels were not meso- or macro-porous and the active sites on the surface would essentially contribute to progress the reaction.

\section{Ring Opening Polymerization}

At first, the polymerizations of oxetane in the presence of a catalytic amount of the silicate gels 1a-d, 2a-c, or 3a were conducted at $20^{\circ} \mathrm{C}$ in $1.7[\mathrm{M}]$ solution of benzene to elucidate the activities of the catalysts. In the polymerizations, the amount of rare earth metal contained in the gel was adjusted to be $10 \mathrm{~mol} \%$ to oxetane. The silicate gels were calcined at $700{ }^{\circ} \mathrm{C}$ before use. The results were listed in Table II. The conversion was calculated on the basis of ${ }^{1} \mathrm{H}$ NMR spectral data. As shown in Figure 1, the signals assigned to the protons of methylene bonded to oxygen in oxetane and POx were appeared at 4.65 and $3.49 \mathrm{ppm}$, respectively. The signals due to the other methylene protons were observed at $2.61 \mathrm{ppm}$ for oxetane and $1.84 \mathrm{ppm}$ for POx, respectively. These could be distinguished easily and were utilized for the calculation of the conversions of oxetane in all the polymerizations mentioned here. The isolated yields of POx were almost in accord with the values of the conversion. This indicated the ring opening reaction of oxetane proceeded primarily to form the corresponding polymer.

Among the silicate gels, yttrium silicates $\mathbf{1}$ showed the most effective catalytic activities for the ring opening polymerization, in which the polymer POx was obtained in the high yields over $85 \%$. Especially, in the use of 1a, the polymerization proceeded to give POx almost quantitatively (Table II, Run 1). The silicate 1a, containing a half molar amount of $\mathrm{Y}$ to $\mathrm{Si}$, was the most effective catalyst among the yttrium silicates 1 used here. The silicate gels, showing the molar ratio of $\mathrm{Y} / \mathrm{Si}$ was over 1 , have not been examined as the catalysts, Such silicate gel involving a higher molar ratio of rare earth metal to $\mathrm{Si}$ should be mostly consisted of the metal oxide structures. The structure seemed to show no catalytic activity 


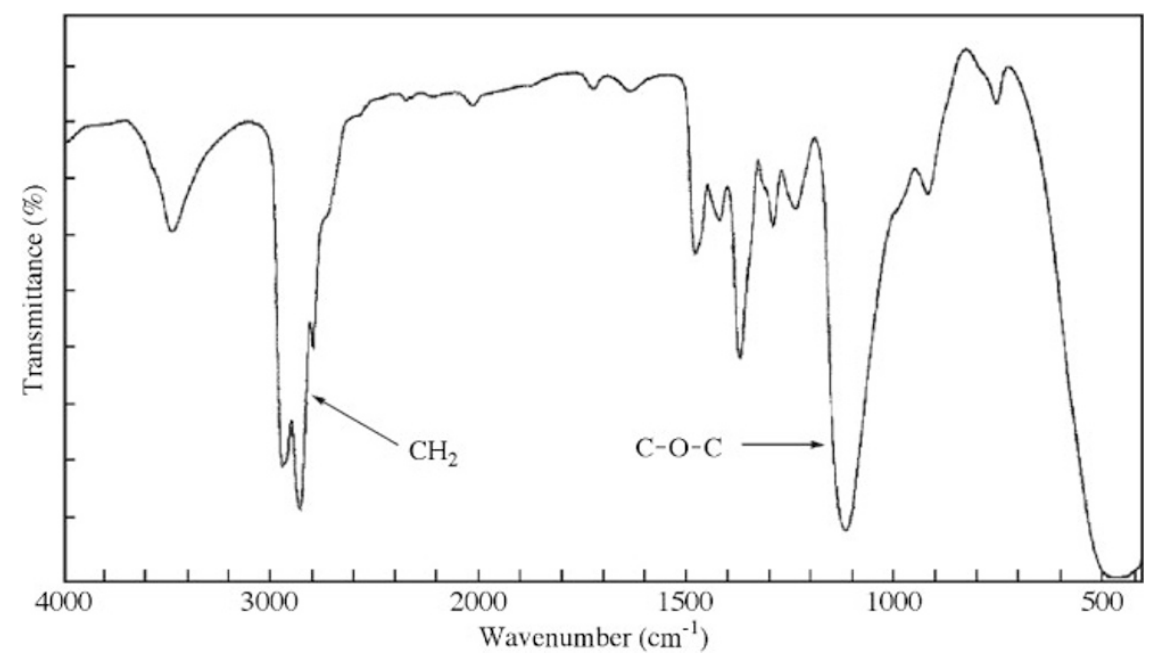

Figure 2. IR spectrum (neat) of POx (Table II, Run 1).

for the polymerization, since the independent experiments using the oxides or chlorides of the rare earth metals as the catalysts were unsuccessful and no polymer was obtained under the analogous conditions. Therefore, in this work, the silicates, which showed the molar ratios of $\mathrm{Si} /$ rare earth metal were over 2 , were employed as the catalysts. In the series using the neodymium silicates, the use of $\mathbf{2 a}$, which contained a higher molar ratio of $\mathrm{Nd}$ than other neodymium silicates $\mathbf{2 b}$ and $\mathbf{2 c}$, recorded the high yield of POx such as 75\% (Table II, Run 5, 6, and 7). In comparison with the efficiencies of the polymerization, the yttrium silicate $\mathbf{1}$ showed the better catalytic activity than the silicate of neodymium $\mathbf{2}$ and samarium $\mathbf{3}$ (Table II, Run 1, 5, and 8). This reflected the reported Lewis acidities of the rare earth metals, in which $\mathrm{Y}$ shows a stronger acidity than $\mathrm{Nd}$ and $\mathrm{Sm} .{ }^{35}$ Consequently, the silicate gel consisted of $\mathrm{Si}$ and $\mathrm{Y}$ was thought to be the stronger solid acid and more effective catalyst for the oxetane polymerization than those contained Nd or Sm. However, no correlation between the kind of the rare earth metals in the silicates and $M_{\mathrm{n}} \mathrm{s}$ of POx was observed. All the $M_{\mathrm{n}}$ s estimated by GPC were in the region of 4000 to 5800 . For an example, the GPC chromatogram of POx obtained in the presence of 1a was shown in Figure 3.

On the basis of the results mentioned above, the following experiments were conducted to get more fundamentally information on the solid acid polymerizations of oxetane by using the catalyst 1a. The results were shown in Table III. When the molar ratios of $\mathrm{Y}$ to oxetane were changed to 1 and $5 \mathrm{~mol} \%$, the polymerizations in benzene solution proceeded to give POx in the lower yields such as 25 and $85 \%$, respectively (Table III, Run 3 and 4). Under the bulk conditions, the yield of POx was improved to be $60 \%$ even in the molar ratio of $\mathrm{Y}$ to oxetane was only $1 \mathrm{~mol} \%$

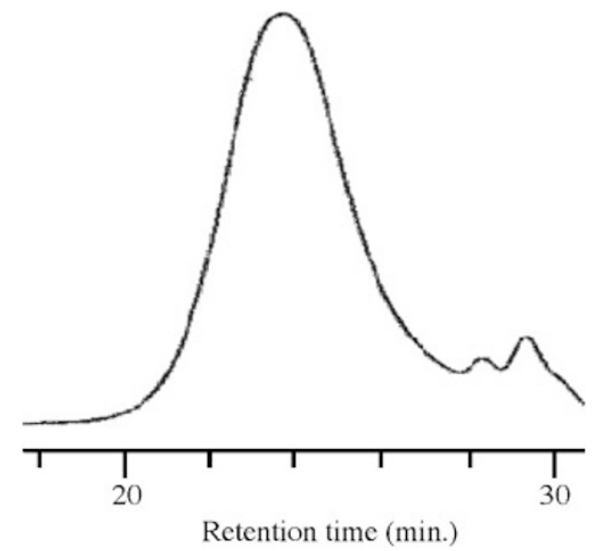

Figure 3. GPC chromatogram of POx (Table II, Run 1).

(Table III, Run 1). The most effective molar ratio of $\mathrm{Y}$ in 1a to oxetane was $10 \mathrm{~mol} \%$. The polymerizations, conducted under solvent-free conditions and also in a benzene solution with the silicate gel showing such molar ratio of $\mathrm{Y}$ to oxetane, proceeded to give POx almost quantitatively (Table III, Run 2 and 5). In addition, the catalyst was reusable. Even in the third use of 1a, POx was obtained in a high yield (Table III, Run 7). However, 1a had to be calcined at $700{ }^{\circ} \mathrm{C}$ for $1 \mathrm{~h}$ before reusing. When the treatment was conducted below $500^{\circ} \mathrm{C}$, no catalytic activity of 1a was observed. This may indicate that the calcination at the high temperature is required not only to remove methanol, $\mathrm{H}_{2} \mathrm{O}$, and/or the products covering the catalytic sites on the surface of 1a, but also to reform the effective silicate structure again.

The solvent effects on the efficiencies of the polymerization were examined. In the polymerizations using the polar solvents such as acetone and acrylonitrile, the yields of POx retained in the range from 58 to 65\% (Table III, Run 11 and 13). These polar solvents 
showed no favorable effect on the polymerization. The results may demonstrate that the polar solvents cover the active sites on 1a located around Y and/or the cationic species generated from oxetane and make the contact with the oxetane monomer difficult.

In all the IR spectra of POxs, a weak absorbance around $3500 \mathrm{~cm}^{-1}$ assigned to hydroxyl group was observed. An example was shown in Figure 2. This indicated that POx possessed hydroxyl groups as the end groups, which seemed to be introduced by terminating and/or initiating processes. In the later case, the initiators for the polymerization were speculated to be silanol groups and/or $\mathrm{H}_{2} \mathrm{O}$ contained as an impurity. The following results may present the preliminary information on such mechanistic aspects of the polymerization. Several reagents, acetic acid, methanol, isopropyl alcohol, or $\mathrm{H}_{2} \mathrm{O}$, was employed as an additive in the oxetane polymerization. The yields of POx decreased to $c a .75 \%$ in the use of $10 \mathrm{~mol} \%$ of the alcohols to oxetane after the reaction conducted for $18 \mathrm{~h}$. Furthermore, in these examples, the $M_{\mathrm{n}} \mathrm{s}$ of POx, which were in the range from 2600 to 3500, decreased to almost a half of those observed in the polymerizations conducted without any additive. From these results, it may be said that the alcohol participate to the polymerization mainly as a chain transfer reagent. At the same time, the alcohol was thought to cover the active sites on 1a like the polar solvents mentioned above. Consequently, the bulky alcohol, iso-propyl alcohol, was unfavorable to access to the catalytic sites on the surface of 1a. Such steric effects might be appeared in the slight difference of the conversions of oxetane, in which the use of methanol led to the lower conversion, $75 \%$, than that of iso-propyl alcohol, 80\% (Table III, Run 8 and 9). The time-conversion curves as shown in Figure 4 supported such explanations. The rate of polymerization in the pres-

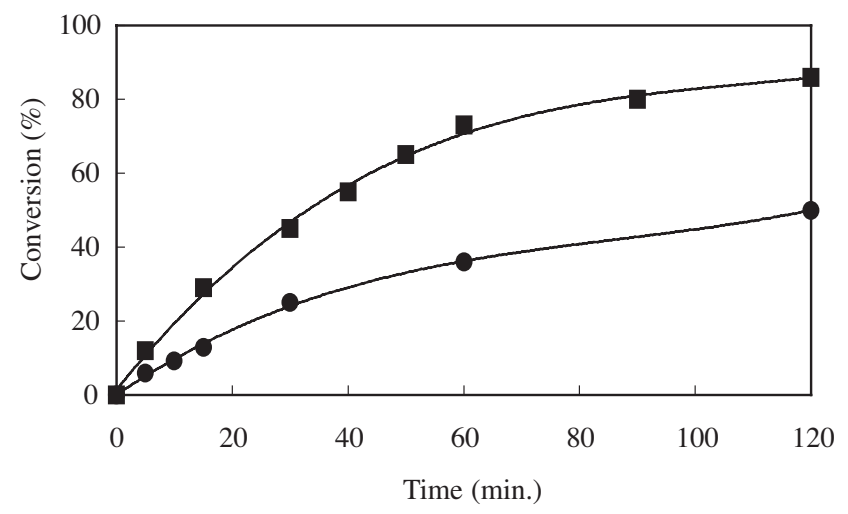

Figure 4. Relationships between time and conversion in the polymerisation of $1.7[\mathrm{M}]$ of oxetane in benzene with $10 \mathrm{~mol} \%$

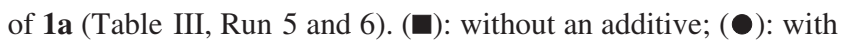
$10 \mathrm{~mol} \%$ of $\mathrm{MeOH}$.

ence of methanol decreased to a half of that conducted without an additive. The conversion- $M_{\mathrm{n}}$ curves of such polymerizations were shown in Figure 5. The $M_{\mathrm{n}}$ s were slightly increased with the increase of the conversions in the both cases, although the linear relationships have not been detected. As a result, the alcohols retarded the ring opening polymerization. In the presence of $\mathrm{H}_{2} \mathrm{O}$, the unsuccessful result was obtained (Table III, Run 11). Since, if Lewis acid sites contributed to initiate the polymerization, $\mathrm{H}_{2} \mathrm{O}$ provided a proton and, at least, the ring opening of oxetane could be observed. This fact may indicate that the silanol groups, activated by $\mathrm{Y}$ as a Lewis acid site, primarily play a roll of the initiator. On the other hand, in the combination of 1a and acetic acid, POx was obtained quantitatively, but the $M_{\mathrm{n}}$ of the polymer decreased to 3100 (Table III, Run 12). This demonstrated that the solid acid stimulated acetic acid to be a co-initiator. In fact, no ring opening polymerization was ob-

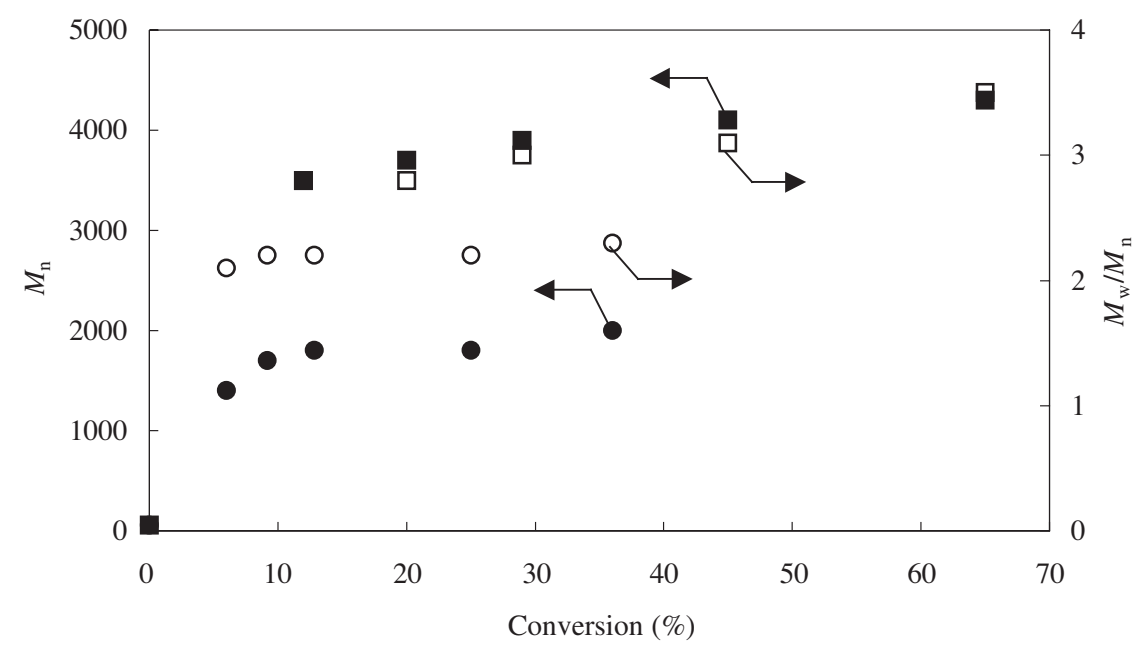

Figure 5. Relationships between conversion, $M_{\mathrm{n}}$, and $M_{\mathrm{w}} / M_{\mathrm{n}}$ in the polymerisation of $1.7[\mathrm{M}]$ of oxetane in benzene with $10 \mathrm{~mol} \%$ of 1a (Table III, Run 5 and 6). ( $\square, \square)$ : without an additive; $(\bullet, \bigcirc)$ : with $10 \mathrm{~mol} \%$ of $\mathrm{MeOH}$. 
Table IV. Polymerization of oxetane derivatives with silicate gel $\mathbf{1 a}^{\mathrm{a}}$

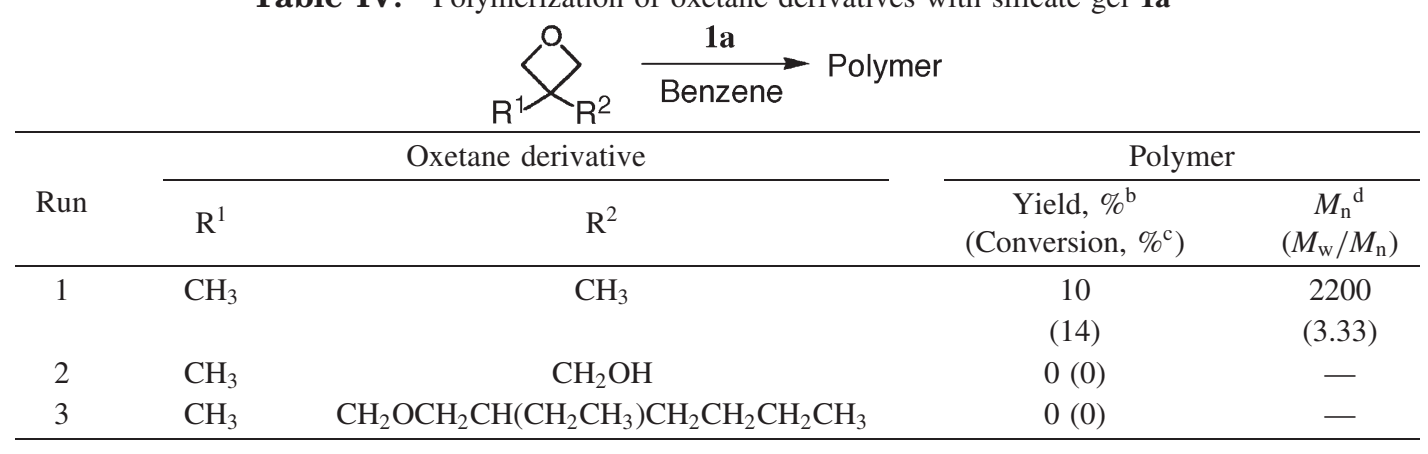

a Polymerisation, using $6.90 \mathrm{mmol}$ of oxetene derivative with 1a containing $0.70 \mathrm{mmol}$ equiv of yttrium, was carried out in $4 \mathrm{~mL}$ of benzne at $20^{\circ} \mathrm{C}$ for $24 \mathrm{~h}{ }^{\mathrm{b}}$ Isolated yield based on the weights of the materials. ${ }^{\mathrm{c}}$ Estimated by ${ }^{1} \mathrm{H}$ NMR spectral data. ${ }^{\mathrm{d}}$ Estimated by GPC (polystyrene standards).

served by the use of only acetic acid without 1a. Further, the use of $n$-butylamine with 1a gave no polymer (Table III, Run 10). The basic reagent, which should neutralize the acid sites, obviously inhibited the polymerization.

The polymerizations of oxetane derivatives such as 3,3-dimethyloxetane, 3-ethyl-3-hydroxymethyloxetane, and 3-ehtyl-3-(2-ethylhexyloxy)methyloxetane in the presence of 1a were tried. The unsuccessful results of these examples were shown in Table IV. The corresponding POx was obtained only in the case of 3,3-dimethyloxetane (Table IV, Run 1). However, the low conversion and the yield such as 14 and $10 \%$, respectively, were recorded. Other oxetane derivatives afforded no polymer and the starting materials were collected after $18 \mathrm{~h}$ reactions under the analogous conditions mentioned above. In the use of second derivative, the hydroxyl group may prevent the polymerization (Table IV, Run 2). While, other derivatives were thought to possess no unsuitable substituent, which affected on the catalytic activities of 1a (Table IV, Run 3). Therefore, the steric hindrance due to the substituents was one of the possible reasons for such unsatisfactory results. The results also suggested that the polymerization proceeded on the surface of the silicate gel, where the bulky substrates could not access easily.

\section{CONCLUSIONS}

The gels obtained from sodium silicate and halides of the rare earth metals such as $\mathrm{Y}, \mathrm{Nd}$, and $\mathrm{Sm}$, which should contain the metal silicate structures, were shown to be the usable solid catalysts for the ring opening polymerization of oxetane. In the polymerization, the silicate gel was thought to act as an acid to generate cation species. Actually, the efficiency of the polymerization reflected Lewis acidity of the metals. Two main advantages were shown in the polymerization system using the solid acids that the catalyst could be removed from the mixture of products by simple filtration and recycled without a loss of catalytic activity. The reuse of the catalyst 1a after the calcination at $700{ }^{\circ} \mathrm{C}$ showed the formation of POx in a high yield was observed even in the third use of $\mathbf{1 a}$.

The examinations mentioned here aimed to develop the synthetic use of the silicate gel, but not conducted from a mechanistic view. However, the preliminary information was obtained. The results observed in the polymerizations using several additives suggested that the silanol group around the rare earth metal contributed to initiate the polymerization. Of course, the possibility of the direct contact of oxetane and rare earth metal species in the silicate cannot be excluded. At least, it may be said that the initiating step proceeds on the surface of the silicate gel and the generated cation species stay around there, where the access of bulky substrate is unfavorable. Those speculated steps in the polymerization were shown in Scheme 2.

More detailed experiments are required to discuss the mechanistic aspects of this cationic ring opening reaction. Along with such views, the investigations utilizing the rare earth metal silicate as a solid acid catalyst for the cationic polymerizations have been continuously progressed and the results will be presented in near future.

\section{REFERENCES}

1. K. Arata and K. Tanabe, Catal. Rev.-Sci. Eng., 25, 365 (1983).

2. G. W. Kabalka and R. M. Pagni, Tetrahedron, 53, 7999 (1997).

3. G. H. Posner, M. Hulce, and R. K. Rose, Synth. Commun., 11, 737 (1981).

4. E. R.-Hitzky and B. Casal, J. Catal., 92, 291 (1985).

5. M. Onaka, M. Kawai, and Y. Izumi, Chem. Lett., 779 (1985).

6. M. Onaka, A. Ohta, K. Sugita, and Y. Izumi, Appl. Catal. A, 125, 203 (1995).

7. S. Hayase, T. Ito, and M. Wada, J. Polym. Sci., Part A: 
Polym. Chem., 19, 2541 (1981).

8. K. Kageyama, S. Ogino, and T. Aida, Macromolecules, 31, 4069 (1998).

9. K. Kageyama, T. Tatsumi, and T. Aida, Polym. J., 31, 1005 (1999).

10. A. A. Vaidaya and V. G. Kumar, J. Appl. Polym. Sci., 70, 629 (1998).

11. M. Trost, I. Fleming, and S. L. Shreiber, "Comprehensive Organic Synthesis," Vol. 1, Pergamon Press, Elmsford, N.Y., 1991.

12. T. Imamoto, "Lanthanides in Organic Synthesis," Academic Press, New York, N.Y., 1991.

13. S. Agarwal, C. Mast, K. Dehnicke, and A. Greiner, Macromol. Rapid Commun., 21, 195 (2000).

14. H. MA, T. P. Spaniol, and J. Okuda, J. Chem. Soc., Dalton Trans., 4770 (2003).

15. M. Kunioka, Y. Wang, and S. Onozawa, Polym. J., 35, 422 (2003)

16. E. Martin, Ph. Dubois, and R. Jerome, Macromolecules, 36, 5934 (2003).

17. L. Fan, L. Zhang, and Z. Shen, Polym. J., 36, 91 (2004).

18. D. C. Brown, "High-Peak-Powder Nd Glass Laser Systems," Springer-Verlag, Heiderberg, 1981.

19. H. A. Ei-Batai, A. L. Hussein, and A. F. Abbas, J. NonCryst. Solids, 24, 336 (1977).

20. T. Fujiyama, M. Hori, and M. Sasaki, J. Non-Cryst. Solids, 121, 273 (1990).

21. W. V. Moreshead, J.-L. R. Nogues, and H. Krabill, J. NonCryst. Solids, 121, 267 (1990).

22. A. N. Christensen, Z. Kristallogr., 209, 7 (1994).
23. O. Tzvetkov and N. Minkova, J. Mater. Sci., 35, 2435 (2000).

24. T. Yamamoto, T. Matsuyama, T. Tanaka, T. Funabiki, and S. Yoshida, Phys. Chem. Chem. Phys., 1, 2841 (1999).

25. J. V. Crivello and H. Sasaki, J. Macromol. Sci., Part A: Pure Appl. Chem., 30, 189 (1983).

26. H. Sasaki, J. M. Rudzinski, and T. Kakuchi, J. Polym. Sci., Part A: Polym. Chem., 33, 1807 (1995).

27. T. Yashiro, T. Sathou, A. Kameyama, and T. Nishikubo, J. Polym. Sci., Part A: Polym. Chem., 41, 2304 (2003).

28. M. Sangermano, R. Bongionavanni, G. Malucelli, A. Priola, J. Olbrych, A. Harden, and N. Rehnberg, J. Polym. Sci., Part A: Polym. Chem., 42, 1415 (2004).

29. T. Saegusa, H. Fujii, S. Kobayashi, H. Ando, and R. Hasegawa, Macromolecules, 6, 26 (1973).

30. M. Bucquoye and E. Goethals, Makromol. Chem., 179, 1681 (1978).

31. S. Kanoh, T. Nishimura, T. Tsuchida, H. Senda, M. Motoi, M. Takani, and N. Matsuura, Macromol. Chem. Phys., 203, 511 (2002).

32. H. Hasegawa and T. Higashumura, J. Polym. Sci., Polym. Chem. Ed., 18, 611 (1980).

33. G. B. Alexander, J. Am. Chem. Soc., 76, 2094 (1954).

34. H. Nishimura, T. Sugizaki, O. Moriya, and T. Kageyama, Nippon Kagaku Kaishi, 505 (2000).

35. R. Anwander, F. T. Edelmann, and W. A. Herrmann, "Organolanthanoid Chemistry: Synthesis, Structure, Catalysis, Topics in Current Chemistry 179," Springer-Verlag, Berlin, 1996. 